\title{
REVISED STRUCTURE OF CERULENIN
}

\author{
Byron H. Arison and Satoshi ŌMura* \\ Department of Biophysics, Merck Institute for Therapeutic Research \\ Rahway, New Jersey 07065, U.S. A. \\ and \\ Wesleyan University \\ Middletown, Connecticut 06457, U. S. A.* \\ (Received for publication August 25, 1973)
}

\begin{abstract}
An evaluation of the $100 \mathrm{MHz}$ NMR spectrum strongly suggests that the structure of cerulenin is (2S) (3R) 2, 3-epoxy-4-oxo-7, 10-dodecadienoyl amide rather than the $-6,10$-dodecadienoyl amide analog. This conclusion was experimentally supported by a spin-decoupling study in a benzene-chloroform mixed solvent system.
\end{abstract}

The antifungal antibiotic cerulenin ${ }^{11}$ has been isolated from Cephalosporium caerulens ${ }^{21}$. Recently, it was reported that the antibiotic is a potent lipid biosynthesis inhibitor in bacteria, yeast and rat liver ${ }^{3,4,5)}$. From chemical degradation and spectrometric studies, structure (I) was proposed $^{6,7)}$.

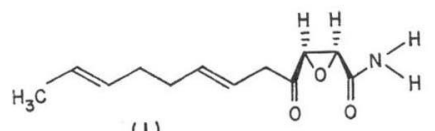

(1)

In this report we wish to describe the evidence that the double bond isomer (II) is more consistent with the NMR $(100 \mathrm{MHz})$ features than structure $(\mathbf{I})$.

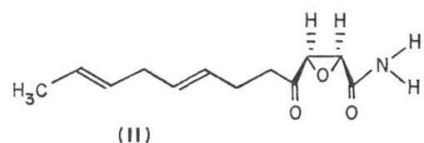

(II)

(2S) (3R) 2, 3-Epoxy-4-oxo-7, 10-dodecadienoyl amide

The NMR spectrum in $\mathrm{CDCl}_{3}$ (Fig. 1) shows that two of the three methylene groups resonate at $\delta 2.70$ while the third occurs at $\delta 2.35$. The multiplicity of the latter (a quartet with second order splitting) strongly suggests that it is one of the two adjacent methylenes in the molecule. Its neighbor must therefore absorb at $\delta 2.70$. The chemical shift difference of $0.35 \mathrm{ppm}$ is difficult to understand in terms of (I) since on first principles one would expect the protons on the dimethylene group to be virtually equivalent. This point is illustrated by the NMR spectrum of geraniol (III) ${ }^{81}$ in which the signals of the dimethylene protons are essentially coincident despite differences in the alkyl substituents attached to the individual double bonds.

$$
\left(\mathrm{H}_{3} \mathrm{C}\right)_{2} \mathrm{C}=\mathrm{CHCH}_{2} \mathrm{CH}_{2} \mathrm{C}\left(\mathrm{CH}_{3}\right)=\mathrm{CHCH}_{2} \mathrm{OH}
$$

(III)

* Present address: The Kitasato Institute, 5-9-1 Shirokane, Minato-ku, Tokyo 108, Japan 
The NMR findings in benzene also pose a problem for Structure I. The most striking difference between the $\mathrm{CDCl}_{3}$ and $\mathrm{C}_{6} \mathrm{D}_{6}$ curves involves the methylene resonances. In the aromatic solvent, two of the three methylene signals appear at $\delta 2.30$ while one occurs at $\delta 2.70$. This change in appearance could result merely from a selective upfield shift of one of the two methylene signals which absorbed at $\delta 2.70$ in $\mathrm{CDCl}_{3}$. (This view necessitates that the remaining two methylene groups are unaffected by the solvent change). The lack of discernible fine structure in the residual methylene signal at $\delta 2.70$ suggests that it is more likely associated with the isolated methylene group*. It would then follow that it is the lower field methylene of the dimethylene group which undergoes the solvent displacement. This, too, is surprising in terms of (I) since benzene solvent shifts normally are appreciable only for protons close to an electron deficient site $^{9,10)}$.

In contrast to (I), the above spectral features are easily reconciled with the double bond isomer (II). Non-equivalence of the dimethylene protons in $\mathrm{CDCl}_{3}$ would reasonably follow from the fact that the attached functional groups are different. The lower field signal at $\delta 2.70$ is preferably assigned to the $\mathrm{CH}_{2} \mathrm{C} / \mathrm{O}$ protons. Its relatively deshielded position can be attributed to the influence of the epoxide, and the upfield shift in benzene is consequent to its proximity to a ketone. The chemical shift of the $=\mathrm{CHCH}_{2} \mathrm{CH}=$ protons $(\delta 2.70)$ compares favorably with the analogous methylene in methyl linolenate ${ }^{111}$.

Further compelling evidence for (II) was obtained from a spin-decoupling study in a $\mathrm{CDCl}_{3}-\mathrm{C}_{6} \mathrm{D}_{6}$ mixed solvent system $\left(85 \% \mathrm{CDCl}_{3} ; 15 \% \mathrm{C}_{6} \mathrm{D}_{6}\right)$ in which all three methylene signals were completely resolved (Fig. 2). The solvent shifted methylene at $\delta 2.43$, heretofore unobserved, is a triplet with second order splitting, and the intensity relationships clearly indicate that it is vicinal to the methylene near $\delta 2.30$. The fact that its multiplicity is not the same as that of its higher field neighbor is by itself strong evidence against (I). Irradiation of the vinylic protons had no effect on this triplet thus indicating the presence of a methylene group

* Since the methylene signal at $\delta 2.35\left(\mathrm{CDCl}_{3}\right)$ showed a well-defined coupling pattern, the multiplicity of its neighbor should be equally evident. 


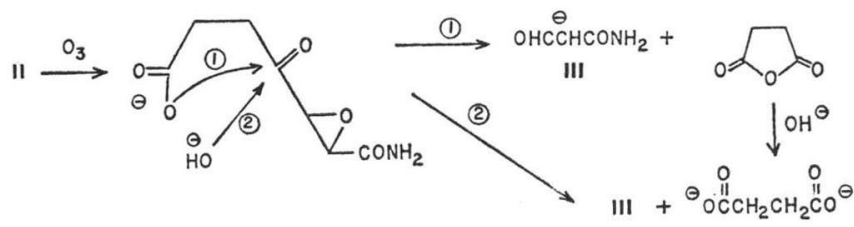

in the molecule which was not vicinal to a vinylic proton. Further, irradiation of the highest field methylene collapsed the methylene triplet to a singlet. Both observed effects are compatible only with (II).

Finally, the formation of disodium succinate from (II) via an ozonolysis reaction can be rationalized by the above schemes*. Both require that the isolation of the oxonolysis product be carried out under alkaline conditions, as was in fact the case ${ }^{61}$.

\section{Acknowledgement}

The authors express their deep gratitude to Professor Max Tishler, Wesleyan University for his hearty encouragement and the valuable suggestions.

\section{References}

1) Sano, Y.; S. Nomura, Y. Kamio, S. Ōmura \& T. Hata: Studies on cerulenin. III. Isolation and physico-chemical properties of cerulenin. J. Antibiotics, Ser. A 20:344 348, 1967

2) Matsumae, A.; Y. Kamio \& T. Hata: Studies on cerulenin. I. Studies on cerulenin producing strain. J. Antibiotics, Ser. A $16: 236 \sim 243,1963$

3) Nomura, S.; T. Horiuchi, S. Ōmura \& T. Hata: The active mechanism of cerulenin. I. Effect of cerulenin on sterol and fatty acid biosynthesis in yeast. J. Biochem. $71: 783 \sim 796,1972$

4) Nomura, S.; T. Horiuchi, T. Hata \& S. Ömura: Inhibition of sterol and fatty acid biosynthesis by cerulenin in cell-free systems of yeast. J. Antibiotics $25: 365 \sim 368,1972$

5) Vance, D.; I. Goldberg, D. Mitsuhashi, K. Bloch, S. Ōmura \& S. Nomura: Inhibition of fatty acid synthetases by the antibiotic cerulenin. Biochem. Biophys. Res. Commun. 48:649 656, 1972

6) Ōmura, S.; M. Katagiri, A. Nakagawa, Y. Sano, S. Nomura \& T. Hata: Studies on cerulenin. V. Structure of cerulenin. J. Antibiotics, Ser. A 20:349 354, 1967

7) Ōmura, S.; A. Nakagawa, K. Sekikawa, M. Otani \& T. Hata: Studies on cerulenin. Vi. Some spectroscopic features of cerulenin. Chem. Pharm. Bull. 17:2361 2363, 1969

8) High Resolution NMR Catalog, Vol. I, No. 279, Varian Associates, 1962

9) Ronayne, J. \& D. H. Williams: Solvent effects in PMR spectroscopy. Ann. Rev. of NMR Spectroscopy, Vol. 2, Academic Press, New York, 1969

10) Bhacca, N.S. \& D. H. Williams: Application of NMR spectroscopy in organic chemistry. Chapter 7, Holden-Day, Inc., San Francisco, 1964

11) High Resolution NMR Catalog, Volume I, No. 337, Varian Associates, 1962

* We are indebted to Dr. Raymond Firestone, Synthetic Chemical Research, Merck \& Co., Inc. for these proposals. 